\title{
Effective heat transfers in packed bed: Experimental and model investigation
}

\author{
Authors

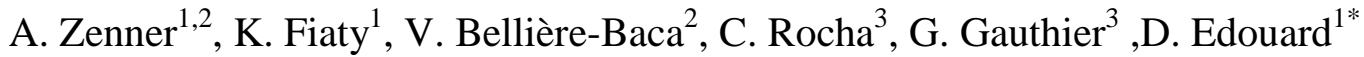 \\ *corresponding author : david.edouard@univ-lyon1.fr \\ ${ }^{1}$ Université Lyon, Université Claude Bernard Lyon 1, CNRS, LAGEP UMR 5007, 43 boulevard \\ du 11 novembre 1918, F-69100, VILLEURBANNE, France \\ ${ }^{2}$ ADISSEO France SAS, Antony Parc 2-10, Antony, France \\ ${ }^{3}$ SOLVAY, Research and Innovation, Brussels, Belgium
}

\begin{abstract}
In industry, many heterogeneous solid/gas reactions are exothermic. Consequently, the radial heat transfer properties can be an important key for the process optimization. In this context, thermal tests were conducted in an innovative laboratory pilot. Radial temperature profiles are measured between a central hot-wire and the cooling jacket of the tube. Two models were presented in order to estimate the heat transfer coefficients from the experimental data. The results are discussed and compared with the main literature correlations. The influence of the particle shapes on heat transfers and the pressure drop is investigated.
\end{abstract}

\section{Key words:}

Fixed bed reactor, heat transfer, thermal conductivity, pseudo-homogeneous model, catalyst supports, particle shapes
Nomenclature
List of symbols
$C p:$ Spectific heat capacity $(\mathrm{J} / \mathrm{kg} / \mathrm{K})$
$D_{\text {wire }}$ : Hot-wire diameter (m)
$D_{t}$ : Internal tube diameter $(\mathrm{m})$
$D_{P V}$ : Diameter of equivalent volume sphere without inner voidage $\left(D p s=D_{c y l} *\left(\frac{3}{2} * \frac{L_{c y l}}{D_{c y l}}\right)^{\frac{1}{3}}\right)$ 


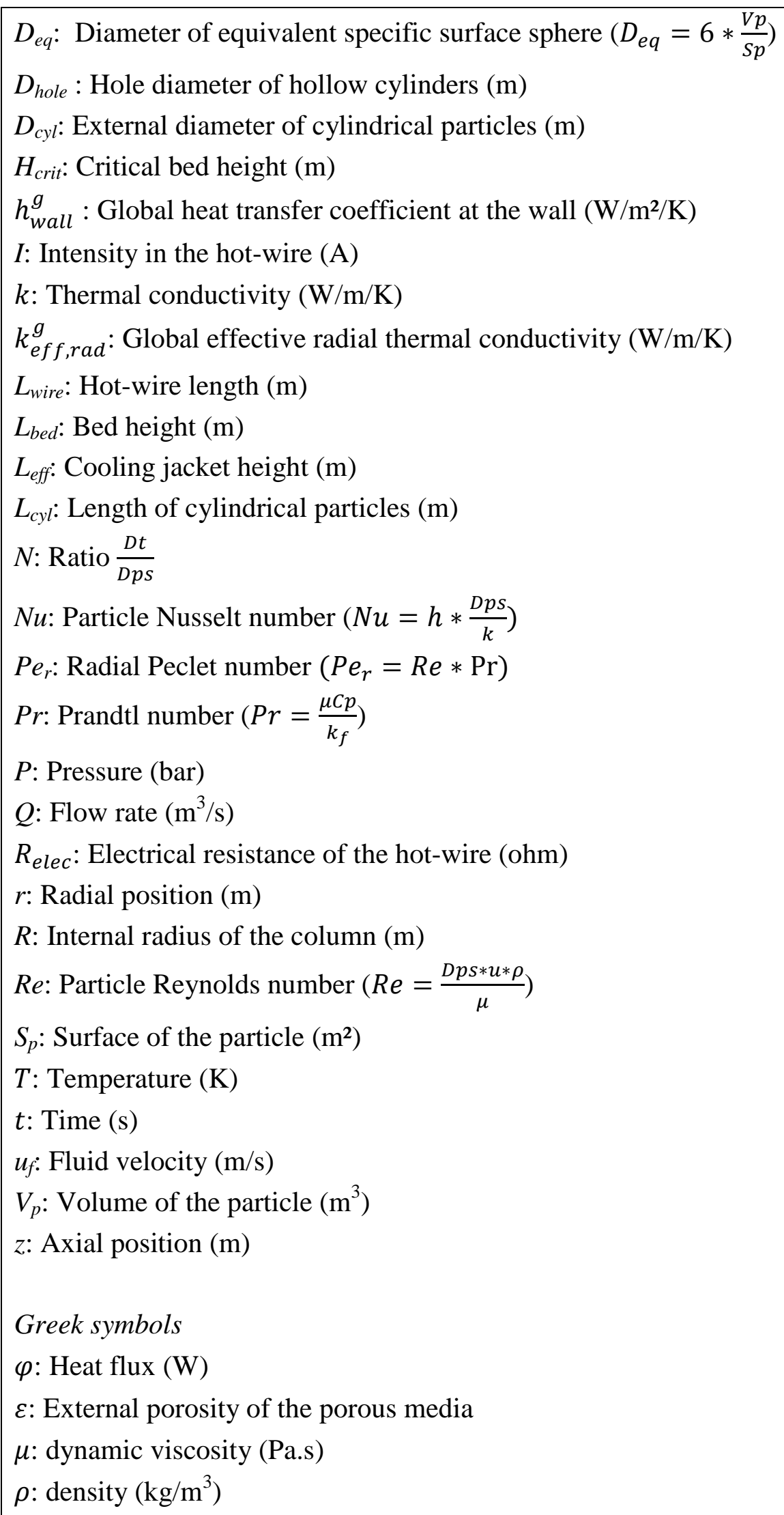


Subscripts and superscripts

ax: axial axis

eff : effective

f: fluid going through the column (air in this work)

g: Global

h: Hot-wire

i: intrinsic

s: solid (catalyst support)

in : Inlet

out: Outlet

rad : radial axis

water: cooling fluid (water in this work)

wall: near the wall on the porous media side

0 : stagnant condition

\section{Introduction}

Since decades, the estimation of heat transfer parameters in packed bed has been a topic of studies in open literature (Bunnell et al., 1949; Yagi and Kunii, 1957; Zehner and Schlünder, 1970; De Wasch and Froment, 1972; Bauer and Schlünder, 1978; Gunn et al., 1987). The effective thermal conductivity $\left(k_{e f f, r a d}^{g}\right)$, the wall heat transfer $\left(h_{\text {wall }}^{g}\right)$ and the pressure drop $(\Delta P)$ are keys for the design of catalytic reactors (Eisfeld and Schnitzlein, 2001; Bhattacharyya and Pei, 1975; Bey and Eigenberger, 2001). These parameters depend on the composition, size, shape of the particles, the bed porosity, experimental conditions, etc...(Dixon et al., 2008; Smirnov et al., 2004; Chueh et al., 2014)

In the case of an exothermic reaction, temperature gradients and hot spots are established in the fixed bed (Zhu et al., 2014; Calverley et al., 2013; Philippe et al., 2009). Beyond the runaway risks, the poor control of the bed temperature induces thermal deactivation, sintering phenomena, and decreases the production yield (Bartholomew, 2001; Forzatti and Lietti, 1999). In this context, the optimization of these three key parameters $\left(k_{e f f, r a d}^{g}, h_{\text {wall }}^{g}, \Delta P\right)$ is necessary.

In the literature, several apparatus were developed in order to measure the radial temperature profile in porous media under gas flow conditions. Experimental apparatus can be distinguished from one another following the method used for heating or cooling the porous media (e.g. heating wall/cold gas in (Wen and Ding, 2006; Edouard et al., 2010; Dixon et al., 2012; Bianchi et al., 2012), exothermic reaction/cooling wall (Pangarkar et al., 2009), endothermic reaction/heating wall (Guo et al., 2014)). Another method consists in heating up metallic spheres generated by 
imposing an electric current passing through the particles (Glaser and Thodos, 1958). This last technic allows simulating an exothermic reaction directly at the surface of particles. However, it requires a particular set up and it is only valuable for the metallic particles. It is also possible to heat the porous media from the center of the column with a hot-wire. Zhu et al. $(2010,2014)$ compared the radial temperature gradients obtained from an exothermic reaction with the data obtained from a central hot-wire device. The authors show that the analogy is possible. However, the effective parameters are not directly measured, and mathematical models are necessary in order to derive these values.

Generally, the 2D-heterogeneous model (De Wasch and Froment, 1971) is used. It consists in a thermal balance on each phase of the porous media, the heat transfer between each phase is also considered. However, under high flow condition, it is frequent to observe a similar temperature between the solid and gas phases in fixed bed reactors. Thus, the 2D-heterogeneous model can be simplified into 2D-pseudo-homogeneous model (Edouard et al., 2010) and the porous media considered as one continuous phase. Moreover, under specific conditions (stabilized axial temperature profile), more drastic simplifications can be done and lead to use the analytical solution of the Fourier's equation in order to estimate the effective thermal conductivity (Zhu et al., 2010).

In this present work, a new experimental apparatus is presented and used to obtain a new set of effective data for different catalytic particles. The well-known 2D-pseudo-homogeneous model and an analytical solution of the Fourier's equation are used in order to derive the global radial

effective thermal conductivity $\left(k_{e f f, r a d}^{g}\right)$ and global heat transfer coefficient at the wall $\left(h_{\text {wall }}^{g}\right)$. The values of the effective parameters obtained are discussed and compared to the literature correlations. Finally, the radial Peclet values are proposed and influence of the shape of the catalytic particles is discussed.

\section{Material and Methods}

\subsection{Experimental devices}


The experimental set-up is shown in Figure 1.



Figure 1 : Sketch of the set-up

The air flow was controlled with a mass flow controller (Brooks SLA5851S). The glass tube is installed vertically with air at the inlet (from the top). At the outlet, a grid $(0.8 \mathrm{~mm}$ mesh) allows to maintain the particles.

The porous medium is heated with a vertical hot wire technology (Thermocoax type ZEZ), which is depicted by the central thick line in Figure 1. The heating zone is positioned at the center of the tube.Voltage and intensity of the power supplier are measured online. A cooling jacket is used. The water flow rate is regulated with mass flow controller (Brooks) and the water temperature is measured at the inlet and outlet of the jacket (Figure 1).

Temperature gradients are imposed between the hot-wire and the cooling jacket; 11 trithermocouples are placed along the effective length (length of the cooling jacket), every 50 millimeters. Thermocouples are inserted radially through the tube wall (Figure 2). 

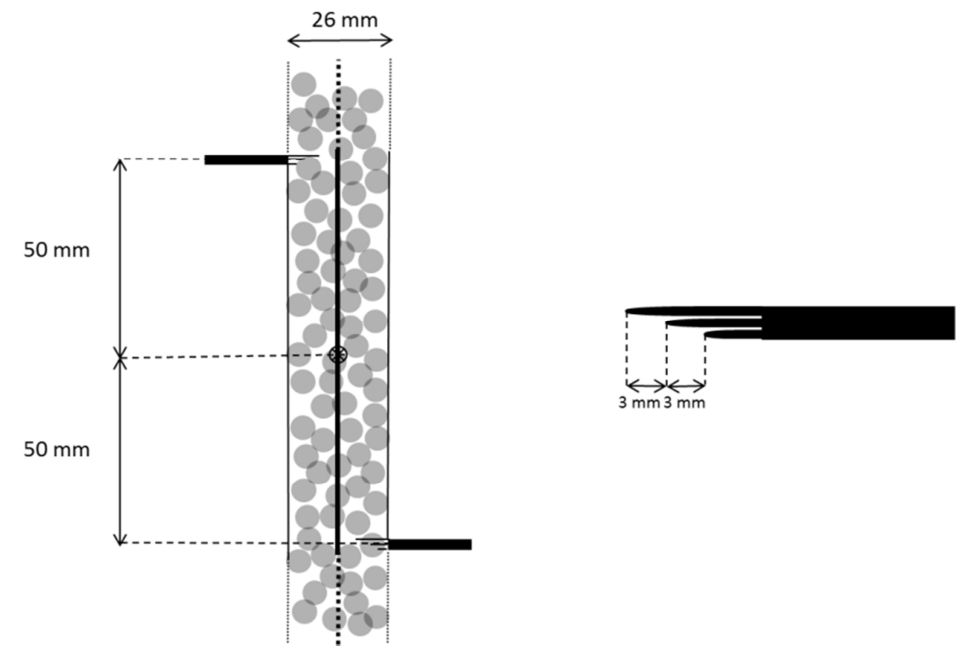

Figure 2: Tri-thermocouple positions and sketch of a tri-thermocouple

The tri-thermocouples are 3 thermocouples type $\mathrm{K}$ (1mm diameter) of different length (at $3 \mathrm{~mm}$ distance from each other) (Figure 2).

The tri- thermocouples are sealed in a $3 \mathrm{~mm}$ diameter sheath in order to facility the airtightness between the glass tube (wall reactor) and the tri-thermocouples (Bola HT Laboratory screw joints technology). The sheath (in alumina) is given as insulation (no conduct heat) by the manufacturer (http://www.tcsa.fr). The sheath is cut at the wall, consequently in the bed, only the thermocouples (type K) are present (figure 2). The radial and axial positions of the trithermocouples are listed in Appendix I. Some of them are placed close to the wire (at $1.5 \mathrm{~mm}$ of the center) and others are close to the internal wall (at $13 \mathrm{~mm}$ of the center).

A differential pressure sensor (Honeywell) is set between the inlet and outlet (which is at the atmospheric pressure) of the column. The pressure drop is measured on the totality of the particle bed $\left(L_{b e d}=0.525 \mathrm{~m}\right)$. A run was done with empty reactor (only the sensors, the wire and the grid are positioned); in this case the pressure drop is negligible (compared to the pressure drop with the filled tube).All sensors were calibrated before use and connected to a PC (data acquisition system).During the loading of the particles in the column, in order to center the hot wire, a set of centralizers is used to maintain the right position of the wire. Next, when the column is filled, they are withdrawn before the experimental measurements

\begin{tabular}{ll}
\hline Parameters & values \\
\hline Hot-wire length $\left(\boldsymbol{L}_{\text {wire }}\right)$ & $0.585 \mathrm{~m}$ \\
Hot-wire diameter $\left(\boldsymbol{D}_{\text {wire }}\right)$ & $1.5 \times 10^{-3} \mathrm{~m}$ \\
Cooling jacket height $\left(\boldsymbol{L}_{\text {eff }}\right)$ & $0.45 \mathrm{~m}$ \\
Internal tube diameter $\left(\boldsymbol{D}_{\boldsymbol{t}}\right)$ & $26 \times 10^{-3} \mathrm{~m}$ \\
\hline
\end{tabular}

Table 1: Characteristic lengths of the set-up 
Air is injected at the inlet of the column (from the top) with a velocity $\left(u_{f}\right)$ in a range of 0.3 to 2.5 $\mathrm{m} / \mathrm{s}$. The corresponding Reynold number varies between 60 and 860 (following the particles tested). The heat flux delivered by the wire (Eq.1) is calculated from the measured intensity and the electrical resistance of the wire $\left(R_{\text {elec }}\right)$ given by the manufacturer.

$\varphi_{h, \text { tot }}=R_{\text {elec }} * I^{2}$

The heat is homogeneous distribution along the length and the heat generated along the effective length of the wire $\left(L_{e f f},\right)$ is given by (Eq.2)

$\varphi_{h}=R_{e l e c} * I^{2} * \frac{L_{e f f}}{L_{\text {wire }}}$

The heat flux removed by cooling jacket is given by (Eq.3).

$\varphi_{w}=Q_{w} * C p_{w} * \rho_{w} * \Delta T_{w}$

The water flow rate $\left(Q_{w}\right)$ is imposed at $175 \mathrm{~mL} / \mathrm{min}$. As a consequence, a difference of temperature is noticed between the water temperature inlet $\left(T_{\text {water, in }}\right)$ and outlet $\left(T_{\text {water,out }}\right) . \Delta T_{w}$ depends on the experimental conditions and the tested particles.

\subsection{Packed bed tested}

In this work, only ceramic particles were tested, due to their interesting thermal, mechanical properties and costs (Vatcha, 1998). Effectively, the ceramics are often used as catalyst carrier for reactions in drastic conditions (oxidative medium, high temperatures, etc...). Two groups of ceramics are studied, oxide ceramics such as Alumina silicon $(\mathrm{Al} / \mathrm{Si})$ and Zirconium $\left(\mathrm{ZrO}_{2}\right)$, and the carbide silicon with two different phases $\alpha \mathrm{SiC}$ and $\beta \mathrm{SiC}(\mathrm{Xu}$ et al., 1992). These materials have distinct thermal properties including the intrinsic conductivity $\left(k_{i}\right)$. Several particle shapes such as spheres and cylinders (full and hollow cylinders) are also studied. Particle compositions, sizes and shapes are reported in Table 2. In this table, diameter of equivalent spherical (with the same volume - $D_{P V}$ ) and diameter of equivalent spherical (with the same specific surface area $\left.D_{e q}\right)$ are also reported. Those values are further used to make comparison with literature correlations. 


\begin{tabular}{cccccccc}
\hline Composition & $\mathbf{Z r O}_{\mathbf{2}}$ & $\mathbf{A l} / \mathbf{S i}$ & $\boldsymbol{\alpha S i C}$ & $\boldsymbol{\beta S i C}$ & $\boldsymbol{\beta S i C}$ & $\boldsymbol{\beta S i C}$ & $\boldsymbol{\beta S i C}$ \\
\hline Shapes & Spheres & Spheres & Spheres & Spheres & Full cylinders & Full cylinders & Hollow cylinders \\
Dimensions $(\mathbf{m m})$ & 3 & 5.2 & 5.1 & 5.4 & $4.7 \times 5.3^{*}$ & $3.8 \times 8.3^{*}$ & $4.9 \times 4.9 \times 3 * *$ \\
Ratio $\mathbf{L c y l} / \mathbf{D} \boldsymbol{c y l} \boldsymbol{l}$ & & & & & 1.1 & 2.2 & 1 \\
$\boldsymbol{k}_{\boldsymbol{i}}(\mathbf{W} / \mathbf{m} / \mathbf{K})$ & 3.3 & 1.5 & 100 & 4.5 & 4.5 & 4.5 & 4.5 \\
$\boldsymbol{D}_{\boldsymbol{P V}}(\mathbf{m m})$ & 3 & 5.2 & 5.1 & 5.4 & 5.6 & 5.7 & 5.6 \\
$\boldsymbol{D}_{\boldsymbol{e q}}(\mathbf{m m})$ & 3 & 5.2 & 5.1 & 5.4 & 4.9 & 4.7 & 3.8 \\
$\boldsymbol{\varepsilon}$ & 0.39 & 0.44 & 0.44 & 0.45 & 0.45 & 0.47 & 0.62 \\
\hline
\end{tabular}

$* D_{c y l} \times L_{c y l}$

** $D_{\text {cyl }} \mathrm{x} L_{c y l} \mathrm{x} D_{\text {hole }}$

Table 2: Particle characteristics

The intrinsic thermal conductivities are given by the manufacturers.

Experiments are carried out for different gas velocities $\left(u_{f}\right)$ and for different values of $\frac{D_{t}}{D_{P S}}<9$.

$\mathrm{ZrO}_{2}$ spheres of $3 \mathrm{~mm}$ diameter do not have internal porosity and the intrinsic conductivity is well known. Thus, $\mathrm{ZrO}_{2}$ spheres can be used as a reference in the following modelling part.

\subsection{Method and Validation}

As noticed previously, the equipment was designed in order to less disturb the heat and mass transfers. In this context, the diameter of the central hot-wire has been optimized $\left(D_{\text {wire }}=1.5 \times 10^{-}\right.$ ${ }^{3} \mathrm{~m}$ ) in order to deliver enough energy to impose a radial gradient of temperature. The residence time distribution (RTD) curves (obtained with and without the hot-wire and thermocouples) are compared in order to check the possible effect of the equipment. Under gas flow condition, the well-known method of inert tracer (see Saber et al. (2012) for the instance) is used.

An example of the RTD curves (with and without equipment) obtained using Saber et al. (2012) method is shown in Figure 3. 




Figure 3: RTD for spheres and hollow cylinders $u_{f}=0.52 \mathrm{~m} / \mathrm{s}$

The RTD curves for the spheres with and without equipment (tri-thermocouple and hot-wire) are very similar. At the contrary, the RTD curves for another packing are different. Consequently, we can assume that the presence of equipment plays only a minor effect on the established flow and at the contrary; the characteristics of the packed-bed (porosity, size and shape of the particles) are first order. We assume that the plug flow prevails along the $\mathrm{z}$ axis.

According to Ergun (1952), the pressure drop of a packed bed depends on the morphological parameters of the bed : the sphere diameter $(D p)$ and the external porosity $(\varepsilon)$ as well as the fluid velocity, the physical characteristics of the fluid and two empirical parameters A and B. Macdonald et al. (1979) extended the Ergun equation to other particle shapes using the equivalent sphere diameter $\left(D p_{e q}\right)$ and set the empirical parameters $\mathrm{A}=180$ and $1.8<\mathrm{B}<4$ depending on the roughness of the particles.

$\frac{\Delta P}{L}=\mathrm{A} * \frac{\mu_{f} *(1-\varepsilon)^{2}}{D p_{e q} q^{2} \varepsilon^{3}} * u_{f}+B * \frac{\rho_{f}(1-\varepsilon)}{D p_{e q} * \varepsilon^{3}} * u_{f}^{2}$ 
Several authors highlighted that in condition of low ratio $D t / D p$ (namely $N$ ), the wall effect must be taken into account in the predicting equation of the pressure drop (Eisfeld and Schnitzlein, 2001; Romkes et al., 2003; Dixon, 1988).

Eisfeld and Schnitzlein (2001) state the coefficients A and B as a function of structural parameters and other empirical coefficients:

$$
\begin{aligned}
& A=K 1 * A w^{2} \\
& B=\frac{A w}{B w} \\
& A w=1+\frac{2}{3\left(\frac{D t}{D p_{e q}}\right)(1-\varepsilon)} \\
& B w=\left(k 1\left(\frac{D p_{e q}}{D t}\right)^{2}+k 2\right)^{2}
\end{aligned}
$$

For examples of coefficients values $(K 1, k 1$ and $k 2)$ see Eisfeld and Schnitzlein (2001).

In our work, we have compared the experimental data with the Macdonald's correlation considering the values of empirical coefficients of Eisfeld and Schnitzlein (2001).

It is very clear that the shape of the particles affects the pressure drop. The composition has no effect on the pressure drop, only the size and the shape of the particle are important parameters (Figure 4).

The parameters $\mathrm{A}$ and $\mathrm{B}$ are estimated from the experimental data and compared to the values given by Eqs. 4-1 and 4-2.

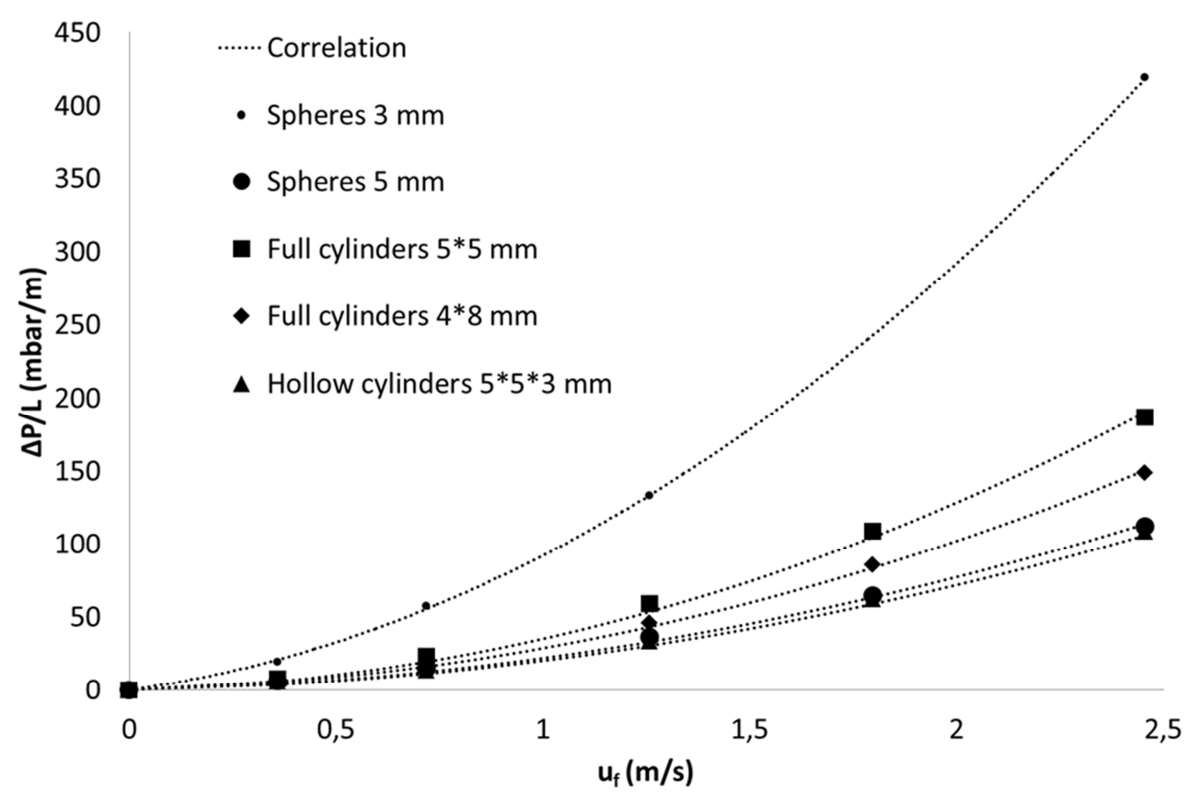

Figure 4: Experimental pressure drop vs equation (4) with fitted A and B parameters ( 


\begin{tabular}{ccccc}
\hline & Calculated $\boldsymbol{B}$ & Estimated $\boldsymbol{B}$ & Calculated A & Estimated A \\
\hline Spheres & & & & \\
\hline $\mathbf{5} \mathbf{~ m m}$ & 1.48 & 1.29 & 239 & 253 \\
$\mathbf{3} \mathbf{~ m m}$ & 1.44 & 1.47 & 195 & 206 \\
Cylinders & & & & \\
\cline { 1 - 4 } Full 4x8 mm & 1.75 & 1.83 & 288 & 295 \\
Full 5x5 mm & 1.75 & 2.02 & 284 & 275 \\
Hollow 5x5 mm & 1.89 & 2.37 & 264 & 301 \\
\hline
\end{tabular}

Table 3)

\begin{tabular}{ccccc}
\hline & Calculated $\boldsymbol{B}$ & Estimated $\boldsymbol{B}$ & Calculated A & Estimated A \\
\hline Spheres & & & & \\
\hline $\mathbf{5} \mathbf{~ m m}$ & 1.48 & 1.29 & 239 & 253 \\
$\mathbf{3} \mathbf{~ m m}$ & 1.44 & 1.47 & 195 & 206 \\
Cylinders & & & & \\
\hline Full 4x8 mm & 1.75 & 1.83 & 288 & 295 \\
Full 5x5 mm & 1.75 & 2.02 & 284 & 275 \\
Hollow 5x5 mm & 1.89 & 2.37 & 264 & 301 \\
\hline
\end{tabular}

Table 3: Estimated and calculated (from correlations (Eisfeld and Schnitzlein, 2001)) parameters

In

\begin{tabular}{|c|c|c|c|c|}
\hline & Calculated $B$ & Estimated $B$ & Calculated A & Estimated A \\
\hline \multicolumn{5}{|l|}{ Spheres } \\
\hline $5 \mathrm{~mm}$ & 1.48 & 1.29 & 239 & 253 \\
\hline $3 \mathrm{~mm}$ & 1.44 & 1.47 & 195 & 206 \\
\hline \multicolumn{5}{|l|}{ Cylinders } \\
\hline Full 4x8 mm & 1.75 & 1.83 & 288 & 295 \\
\hline Full 5x5 mm & 1.75 & 2.02 & 284 & 275 \\
\hline Hollow $5 \times 5$ mm & 1.89 & 2.37 & 264 & 301 \\
\hline
\end{tabular}


Table 3, the estimated values of A and B are very close to the calculated values and seems confirm the reliability of the pressure drop measured with the set up. The deviations between calculated and estimated values are respectively around of 5\% for $\mathrm{A}$ and around $15 \%$ for $\mathrm{B}$. The equation 42 is not available for hollow cylinders. According to Nemec and Levec (2005), the value of B must be higher for hollow than for full cylinder. Indeed, the hollows increase the friction area and consequently create turbulences in the porous medium. These pressure drop values and the previous results (RTD curves, Figure 3) confirm that the packings are not very disturbed by the presence of the intrusive apparatus; consequently the study of the heat transfer can be made with a good confidence.

\section{Results and discussion}

\subsection{Modeling: Pseudo-homogeneous model and analytical model}

In this section, we propose a simplified procedure based on analytic solution in order to estimate directly the global heat transfer from the experimental data. This simplified model is compared to the well-known pseudo-homogenous model which is rapidly presented and validated in the following paragraph. In open literature, the 2D-heterogeneous (2D-HT) and 2D-pseudohomogeneous (2D-PH) models are usually used for heat transfer modelling in fixed bed reactors (Edouard et al., 2010), (Bianchi et al., 2012), (De Wasch and Froment, 1971). 2D-HT is composed of two heat balances (one on each phase) coupled by heat exchange between the solid particles and the fluid phase. It involves 6 effective parameters (radial effective conductivity of the fluid, radial and axial effective conductivities of the solid, solid-fluid heat transfer coefficient, wall heat transfer coefficients (fluid and solid)). According to Edouard et al. (2010), the estimation of many parameters causes convergence issues and a wide confidence interval. In this way, the 2D-HT was mathematically simplified by expressing the gas temperature as a function of the solid temperature (see for instance Edouard et al., 2010). After derivation, this model lumps together the inter-correlated parameters, reducing the number of fitting parameters at 3 global effective parameters (global heat transfer coefficient at the wall, global axial and radial effective conductivities). In this study, the 2D-PH model is thus preferred.

The dynamic 2D-PH model was developed considering that heat capacity of the gas is negligible compared to the solid one. Consequently, the dynamic of the system is given by the solid composition. One radial contribution (namely the global radial effective thermal conductivity) and two axial heat transfer contributions (convection due to the flow and the axial effective thermal conductivity) are taken into account.

The main assumptions are:

1. Plug flow prevails along the $\mathrm{z}$ axis 
2. Radial heat transfer is accounted for by effective gas and solid heat conductivities.

3. Any physical parameter is radially and axially constant.

5. Axial heat conduction by the gas is neglected.

6. Viscous dissipation, work of pressure force, etc. are neglected.

$(1-\varepsilon) \rho_{s} C p_{s} \frac{\partial T}{\partial t}=k_{e f f, r a d}^{g}\left(\frac{\partial^{2} T}{\partial r^{2}}+\frac{1}{r} \frac{\partial T}{\partial r}\right)+k_{e f f, a x}^{g} \frac{\partial^{2} T}{\partial z^{2}}-u_{f} \rho_{f} C p_{f} \frac{\partial T}{\partial z}$

Boundary conditions:

$\forall r, z=0, \frac{\partial T}{\partial z}=\frac{u_{f} \rho_{f} C p_{f}}{k_{e f f, a x}^{g}}\left(T-T_{f, i n}\right)$

$\forall r, z=H, \frac{\partial T}{\partial z}=0$

$\forall z, r=0: \frac{\partial T}{\partial r}=-\frac{\varphi_{h}}{k_{\text {rad,eff }}}$

$\forall z, r=\frac{D t}{2}: \frac{\partial T}{\partial r}=\frac{h_{\text {wall }}^{g}}{k_{\text {eff }, \text { rad }}^{g}}\left(T_{\text {wall }}-T\right)$

At the inlet (5-1), the boundary condition are given by Bianchi et al. (2012). In this work, we assume that the heat flux generated by the wire is only transferred to the porous media by conduction (5-3) phenomena (in other words, no heat transfer due to the forced convection between gas phase and wire is considered).

Normally, these transport equations (Eq. (5)) must be coupled with the steady volume - averaged momentum equation that governs fluid flow in porous media. But, in this work the effect of a radially non-uniform velocity profile has been not considered.

According to Edouard et al. (2010), the global effective parameters of the 2D-PH model depend on the effective parameters of each phase:

$$
\begin{aligned}
& k_{e f f, a x}^{g}=k_{e f f, a x, s}+\frac{\left(u_{f} \rho_{f} C p_{f}\right)^{2}}{h a_{c}} \\
& k_{e f f, r a d}^{g}=k_{e f f, r a d, s}+k_{e f f, r a d, f} \\
& h_{w a l l}^{g}=\frac{k_{e f f, r a d}^{g}}{\left(\frac{1}{2}\right)\left(\frac{k_{e f f, r a d, s}}{h_{w a l l, s}}+\frac{k_{e f f, r a d, f}}{h_{w a l l, f}}\right)}
\end{aligned}
$$

The energy equation of the 2D-PH model was solved using a constant grid spacing along both $z$ and $r$ axis. The special discretization was performed using the standard cell-centered finite difference scheme. In order to obtain a satisfactory temperature profile, 3360 points (60x56) are 
used in simulation. The temperature profiles obtained with $2 \mathrm{D}-\mathrm{PH}$ model are compared at the experimental data $\left(\mathrm{ZrO}_{2}\right.$ spheres) in Figures 5 and 6. Figure 5, we plot the axial temperature profiles. Consequently, the exact thermocouple positions are approximated on the graph. For $r \sim 7.5 \mathrm{~mm}$ (given in the legend), the exact values of the radial coordinate $(r)$ are given in Appendix I and are between $6.6<r<7.7 \mathrm{~mm}$. Figures 6 and 7 , the real value of $r$ are used on the graphs.

The agreement between 2D-PH model and experiment data is good. However, near of the hot wire, the 2D-PH model not describes very well the beginning of the bed. Maybe, the difference is due to the temperature of the hot wire which is disturbed by the fluid near the entrance. The values of the effective parameters used in simulation (Table 4) are derived from the usual correlations of Zehner-Schlünder-Bauer (Zehner and Schlünder, 1970; Bauer and Schlünder, 1978).

\begin{tabular}{cc}
\hline Parameters & values \\
\hline $\boldsymbol{u}_{f}(\mathrm{~m} / \mathrm{s})$ & 1.26 \\
$\boldsymbol{k}_{\boldsymbol{e f f , r a d}}^{\boldsymbol{g}}(\mathrm{W} / \mathrm{m} / \mathbf{K})$ & 1.04 \\
$\boldsymbol{k}_{\boldsymbol{e f f , a x}}^{\boldsymbol{g}}(\mathrm{W} / \mathrm{m} / \mathbf{K})$ & 8.55 \\
$\boldsymbol{h}_{\boldsymbol{w a l l}}^{\boldsymbol{g}}\left(\mathrm{W} / \mathbf{m}^{2} / \mathbf{K}\right)$ & 174.1 \\
\hline
\end{tabular}

Table 4: Simulation parameters

The value of the inlet temperature of the fluid (Eq.5-1) is given directly by the temperatures measured on the top of the bed $(H=0 \mathrm{~m})$. The temperature increase on the first $0.25 \mathrm{~m}$ (Figure 5), next the axial temperature profile is stabilized. The first part is the zone of the reactor where the gas flow pattern is establishing. Close to the wall $(\mathrm{r}=13 \mathrm{~mm})$, after the bed height of $0.25 \mathrm{~m}$ the temperature slowly decreases following the axial coordinate $(\mathrm{z})$ due to the temperature at the inlet cooling jacket. Indeed, cold water is injected from the bottom (countercurrent mode) of the column. 


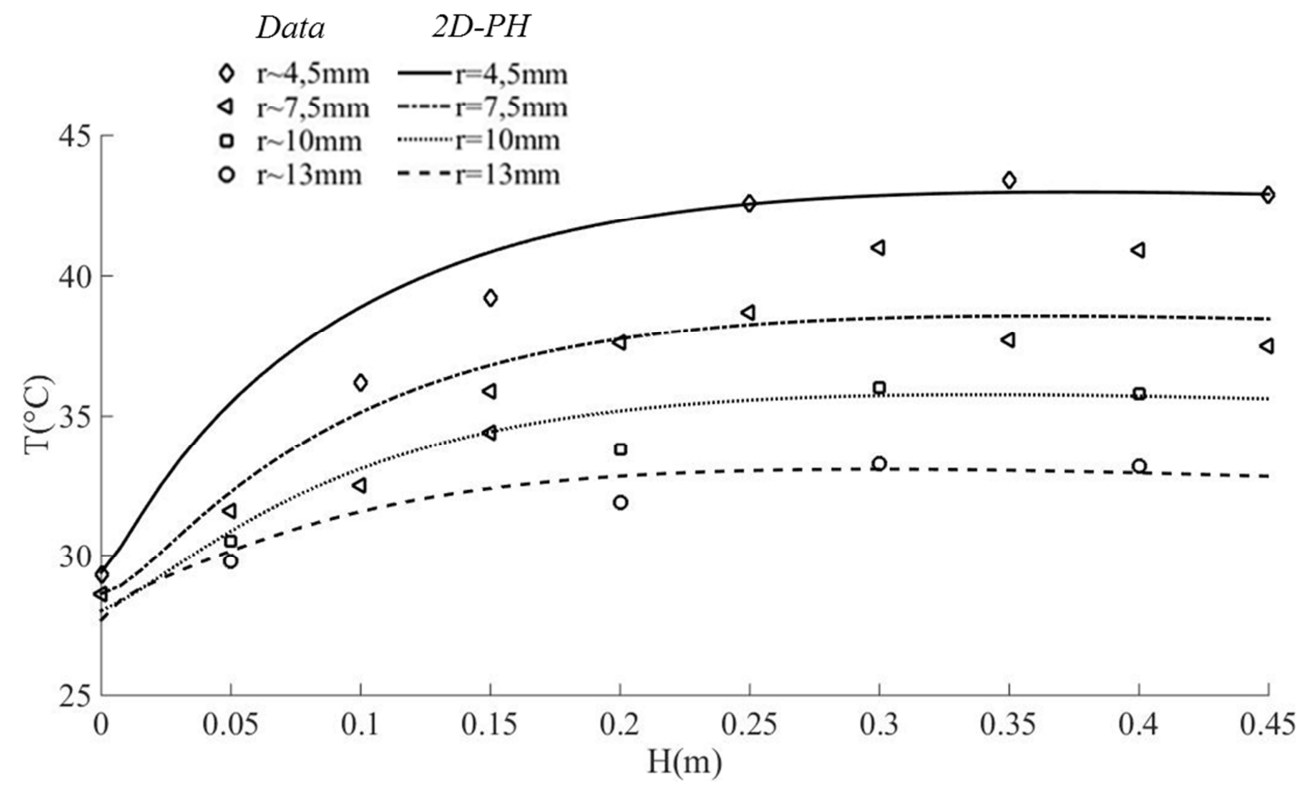

Figure 5 : Axial temperature profiles



Figure 6 : Radial temperature profiles

Analytical model and simplified procedure for the estimation:

In this work, we propose to combine the method proposed by Zhu et al. (2010) (using analytical solution of the Fourier's equation in a cylinder (Eq.7)) for estimated the global radial effective thermal conductivity alone $\left(k_{e f f, r a d}^{g}\right)$ and the approaches proposed by the Bey and Eigenberger (2001) for estimated the heat transfer coefficient $\left(h_{\text {wall }}^{g}\right)$ near of the wall . 
According to Zhu et al. (2010), from the bed height (namely $H_{\text {crit }}$ ), the axial gradient of temperature are flat (see for instance Fig 6). In this condition the radial temperature profiles can be obtained by a simple Fourier's equation (dotted line in Figure 6) and the global radial effective thermal conductivity is then given by:

$k_{e f f, r a d}^{g}=\frac{\varphi_{h}}{2 \pi L_{e f f}} * \frac{\ln \left(\frac{R}{r}\right)}{T-T_{r=R}}$

$T_{r=R}$ is the temperature at the wall in the particle bed side. The value of $H_{c r i t}$ depends on the experimental conditions and tested particles. The value of $H_{c r i t}$ can be determined directly from the experimental data measurements. In the case of the reference particle $\left(\mathrm{ZrO}_{2}\right.$ spheres of $\left.3 \mathrm{~mm}\right)$ and the air velocity $u_{f}=1.26 \mathrm{~m} / \mathrm{s}$, it is easy to see that the value of $H_{c r i t}$ is around of $0.25 \mathrm{~m}$.

$k_{\text {eff,rad }}^{g}$ is estimated from the data of temperature acquired beyond $H_{c r i t}$ with a classical Levenberg-Marquadt algorithm (Matlab software). The Fourier's temperature profile and experimental temperatures are plotted in Figure 7. The uncertainty of $0.5 \mathrm{~mm}$ on the radial position of the thermocouples is also plotted. The uncertainty on the temperature measured by the thermocouples is $0.2{ }^{\circ} \mathrm{C}$ which is too low to be represented on the graph.

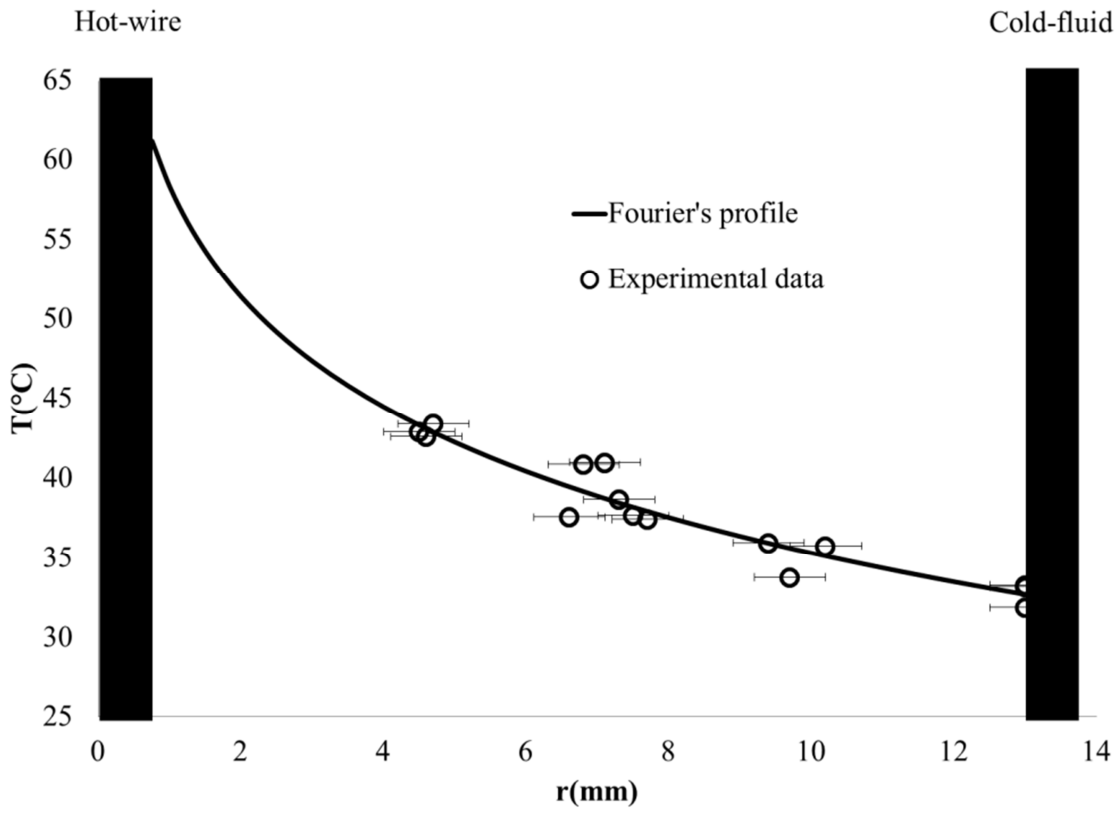

Figure 7: Fourier's temperature profile vs experimental data

In Figure 7, Fourier's equation (7) fits well the experimental data. The uncertainty on $k_{\text {eff,rad }}^{g}$ is derived from the sensitivity study to the different variables (Appendix II). The present method provides an estimation of $k_{\text {eff,rad }}^{g}$ with an uncertainty around of $15 \%$. 
Always from the critical bed height $\left(H_{c r i t}\right)$, and near of the wall, the heat transfer coefficient $\left(h_{\text {wall }}^{g}\right.$ ) can be estimated. Assuming that the heat is carried out only by convection, in this condition a simple heat balance can be established.

$\varphi_{h}=2 \pi R L_{e f f} h_{w a l l}^{g}\left(T_{r=R}-\overline{T_{w a l l}}\right)$

The mean wall temperature $\overline{T_{\text {wall }}}$ is not precisely measured, only the inlet and outlet temperatures of the water ( $T_{\text {water, in }}$ and $T_{\text {water,out }}$ ) are measured. A linear gradient of temperature in the coolant fluid can be assumed. In this work, the difference of temperature between the inlet and outlet varies between $1{ }^{\circ} \mathrm{C}$ and $2^{\circ} \mathrm{C}$ depending on the tested particles and the gas flow rate. The water temperature beyond $H_{c r i t}$ can be approximated by the mean water temperature between $H_{c r i t}$ and the bottom of the cooling jacket $\left(L_{e f f}\right)$ :

$\overline{T_{\text {water }}}=T_{\text {water,in }}+\frac{1}{2}\left(1-\frac{H_{\text {crit }}}{L_{\text {eff }}}\right) *\left(T_{\text {water,out }}-T_{\text {water,in }}\right)$

The flux is transferred by conduction through the thickness of the wall:

$\varphi_{h}=2 \pi k_{\text {glass }} L_{e f f} * \frac{\overline{T_{\text {wall }}}-\overline{T_{\text {water }}}}{\ln \left(\frac{R_{\text {ext }}}{R}\right)}$

Then, by combination of (9) and (10), $\overline{T_{\text {wall }}}$ can be derived (11)

$\overline{T_{\text {wall }}}=\frac{\varphi_{h} \ln \left(\frac{R_{\text {ext }}}{R}\right)}{2 \pi k_{\text {glass }} L_{\text {eff }}}+T_{\text {water }, \text { in }}+\frac{1}{2}\left(1-\frac{H_{\text {crit }}}{L_{\text {eff }}}\right) *\left(T_{\text {water }, \text { out }}-T_{\text {water }, \text { in }}\right)$

The Eq. 11 with the Eqs 7 and 8 allow to estimate the $k_{\text {eff,rad }}^{g}$ and $h_{\text {wall }}$. This is the same set of equations used by Bey and Eigenberger (2001) in order to estimate the effective parameter values between two hot plates. The difference is the expression of the Fourier's equation, indeed the radial profile of temperature is linear between two plates.

In the next paragraph, this simplified procedure is then used for estimated the global radial effective thermal conductivity $\left(k_{e f f, r a d}^{g}\right)$ and the heat transfer coefficient $\left(h_{w a l l}^{g}\right)$ near of the wall. The uncertainties are respectively $15 \%$ and $20 \%$ for all compositions and/or shapes of the tested particles.

3.2. Effective thermal conductivity of spheres 
According to Zehner and Schlünder (1970) and Bauer and Schlünder (1978), the effective thermal conductivity is a combination of the stagnant $\left(k_{e f f, r a d, 0}^{g}\right)$ and dynamic radial thermal conductivity $\left(k_{e f f, r a d, d}\right)$.

$k_{e f f, r a d}^{g}=k_{e f f, r a d, 0}^{g}+k_{e f f, r a d, d}$

With $\frac{k_{e f f, r a d, d}}{k_{f}}=\frac{1}{P e_{r}} * \operatorname{RePr}$

Different correlations can be used to predict the value of radial Peclet number $\left(P e_{r}\right)$. Dixon (2012) listed the main correlations. The author highlighted that $P e_{r}$ is independent of the particle composition. Most of the authors are agreeing that $P e_{r}$ is slightlydependent of the $N$ (ratio $D t / D_{P V}$ ) in a range of 8-12 (with constant $D t$ ) for the spherical particles. Dixon (2012) claims that $P e_{r}$ can be approximate by a constant value $\left(P e_{r}=10\right.$ with an error of $\left.20 \%\right)$.

In Figure 8, the values of $k_{\text {eff,rad }}^{g}$ obtained with the previous method are given for different particles. The linear evolution of the $k_{e f f, r a d}^{g}$ versus the Reynolds number can be observed for all the tested particles.

The values of $P e_{r}$ obtained by the 2D-PH model and the analytical model (Eqs7-11) are compared with the Dixon values in Table 5.

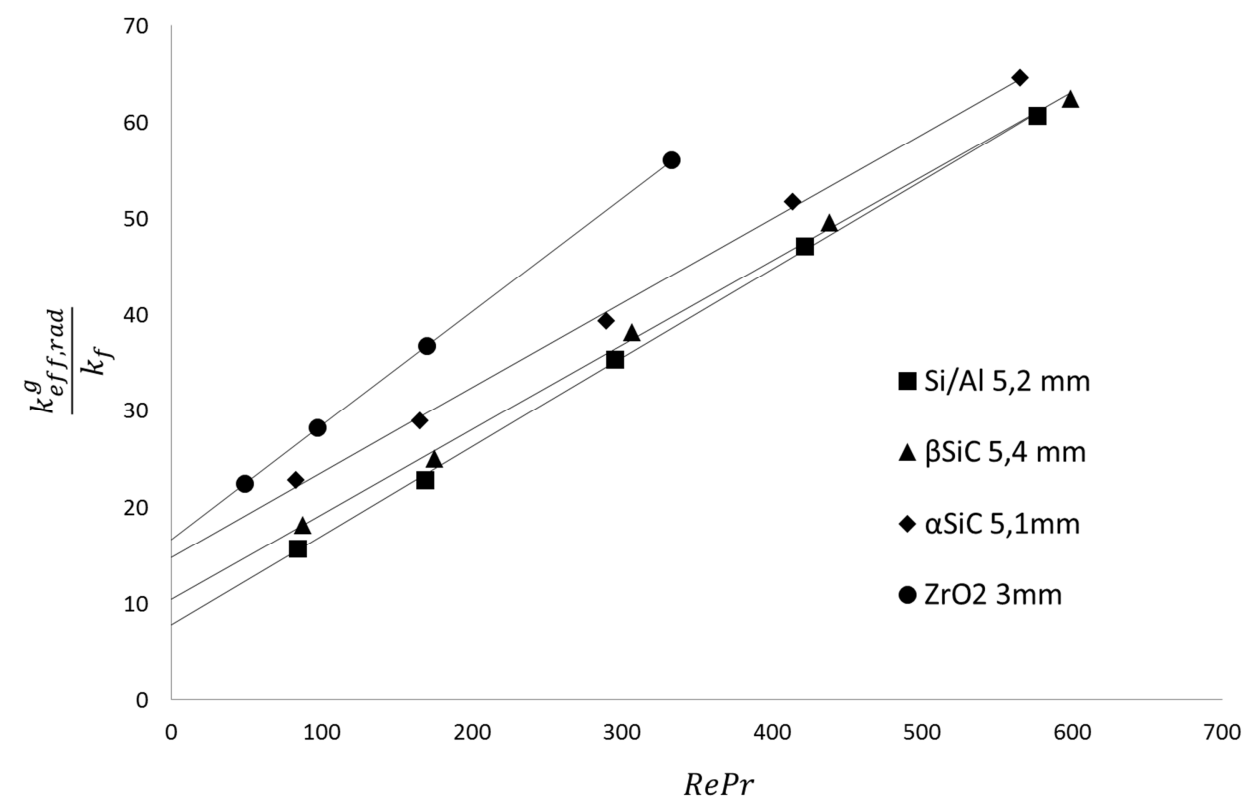

Figure 8: Radial effective thermal conductivity of spheres 


\begin{tabular}{cccc}
\hline Spheres & $\boldsymbol{P e}_{\boldsymbol{r}}(\mathbf{D i x o n}, \mathbf{2 0 1 2})$ & $\boldsymbol{P e}_{\boldsymbol{r}}(\mathbf{2 D}-\mathbf{P H})$ & $\boldsymbol{P e}_{\boldsymbol{r}}$ (Simplified Model) \\
\hline $\boldsymbol{\alpha S i C}$ & 10 & 11.4 & 11.4 \\
$\boldsymbol{\beta S S i C}$ & 10 & 11.4 & 11.3 \\
$\mathbf{S i} / \mathrm{Al}$ & 10 & 10.3 & 10.8 \\
$\mathbf{Z r O}_{2}$ & 10 & 8.5 & 8.5 \\
\hline
\end{tabular}

Table 5: Comparison of the radial Peclet numbers for spheres

$P e_{r}$ (2D-PH) and $P e_{r}$ (Simplified Model- SM) are very similar, and the values are close to the value given by Dixon. The second important parameter is the stagnant contribution $\left(k_{e f f, r a d, 0}^{g}\right)$ which is obtained by linear regression. Results are compared with correlations of the open literature. Van Antwerpen et al. (2010) found that a reasonable accuracy is obtained with the approach of Zehner-Schlünder-Bauer (Zehner and Schlünder, 1970; Bauer and Schlünder, 1978) correlations. In Table 6 , the values of the stagnant effective thermal conductivity estimated from the 2D-PH and SM are presented and compared at the value obtained with the Zehner-SchlünderBauer correlation.

\begin{tabular}{|c|c|c|c|}
\hline Spheres & $\boldsymbol{k}_{\text {eff,rad, } 0}^{g}$ & $k_{e f f, r a d, 0}^{g}(2 \mathrm{D}-\mathrm{PH})$ & $k_{e f f, r a d, 0}^{g}(\mathrm{SM})$ \\
\hline$\overline{\mathrm{aSiC}}$ & $\overline{0.46}$ & $\overline{0.42}$ & 0.40 \\
\hline$\beta S i C$ & 0.28 & 0.29 & 0.28 \\
\hline $\mathbf{S i} / \mathbf{A l}$ & 0.21 & 0.22 & 0.21 \\
\hline $\mathrm{ZrO}_{2}$ & 0.32 & 0.47 & 0.45 \\
\hline
\end{tabular}

The spheres of $\alpha \mathrm{SiC}, \beta \mathrm{SiC}$ and $\mathrm{Si} / \mathrm{Al}$ have the same particle diameter. According to the correlations of Zehner and Schlünder (1970), $k_{\text {eff,rad,0 }}^{g}$ increases when the intrinsic conductivity $\left(k_{i}\right)$ of the material increases for similar sphere sizes. $\mathrm{ZrO}_{2}$ spheres are the smallest particles. According to Zehner and Schlünder (1970) the effective stagnant conductivity for the spheres of $\mathrm{ZrO}_{2} 3 \mathrm{~mm}$ is higher than the one of $\beta \mathrm{SiC} 5.4 \mathrm{~mm}$. In gas/solid systems, $k_{\text {ef } f, r a d, 0}^{g}$ is mostly related to the intrinsic conductivity of the material and the inter-particle contact area. So for the small size particles, it requires a higher number of particles in order to fill the reactor. In other words, the number of inter-particle contacts (contact area) increases with the decreasing porosity of the bulk. The estimated $k_{e f f, r a d, 0}^{g}$ are in relatively good agreement with the expected values. The estimation of $k_{e f f, r a d, 0}^{g}$ is done by linear regression (Fig.8). To measure $k_{\text {eff,rad, } 0}^{g}$ at $\mathrm{Re}=0$ (without natural convection), an technic solution would be to put the tube under vacuum (Sadeghi et al., 2011), unfortunately the pilot used in this work was not designed for such experimental conditions. 


\subsection{Effective thermal conductivity of cylinders}

The same method is used to evaluate the full and hollow cylinders. Dixon (2012) listed and discussed about some correlations and suggested to use $P e_{r}$ equals to 7 and 6 respectively for the full and hollow cylinders.



Figure 9: Radial effective thermal conductivity of cylinders

\begin{tabular}{|c|c|c|c|}
\hline Particles & $\begin{array}{l}P e_{r} \text { (Dixon, } \\
\text { 2012) }\end{array}$ & $P e_{r}(2 \mathrm{D}-\mathrm{PH})$ & $P e_{r}(\mathrm{SM})$ \\
\hline Full cylinders $4 \times 8^{*}$ & 7 & 7.1 & 7.6 \\
\hline Full cylinders $5 \times 5 *$ & 7 & 7.5 & 7.7 \\
\hline Hollow cylinders $5 \times 5 \times 3 * *$ & 6 & 6.4 & 6.5 \\
\hline
\end{tabular}

The estimated radial Peclet from 2D-PH or SM are similar (Table 7). Results are in a good agreement with the correlation and $P e_{r}$ (Hollow cylinders) $<P e_{r}$ (Full cylinders). $P e_{r}$ of the cylinders is lower than the one of the spheres (Table 5), which means that the dynamic effective conductivity $\left(k_{\text {eff,rad,d }}^{g}\right)$ is affected by the morphology of the particles. The cylinders are preferred for the intensification of the radial heat transfer.

The full and hollow cylinders 5x5 have the same external aspect but a different Peclet number; consequently we can think that the internal aspect of the particles plays an important role in the 
distribution of the heat flux in the bed. Figure 9 shows a more important slope for the hollow cylinders than for the full cylinders. The presence of the hole in the particle allows the intensification of heat transfers for high flow rates ( $\operatorname{Re}>450)$, while for the low flow rates, the heat transfers are intensified with the full cylinders. Indeed, according to (12), the effective conductivity is the combination of the stagnant and dynamic conductivities. All the cylinders are in $\beta \mathrm{SiC}$ material, so only the effect of the form of the particle on $k_{e f f, r a d, 0}^{g}$ is reported in Table 8 . For hollow cylinders, the center of the particles is substituted by gas which is less conductive than solid. It confirms that $k_{e f f, r a d, 0}^{g}($ Full cylinders $5 \times 5)>k_{e f f, r a d, 0}^{g}$ (Hollow cylinders 5x5x3).

\begin{tabular}{cccc}
\hline Particles & $\begin{array}{c}\boldsymbol{k}_{\text {eff,rad,0 }} \text { correlation } \\
\text { (Bauer and } \\
\text { Schlünder, 1978b) }\end{array}$ & $\boldsymbol{k}_{\text {eff,rad,0 }}$ (2D-PH) & $\boldsymbol{k}_{\text {eff,rad,0 }}(\mathrm{SM})$ \\
\hline Full cylinders 4x8 & 0.35 & 0.28 & \\
Full cylinders 5x5 & 0.37 & 0.48 & 0.25 \\
Hollow cylinders 5x5x3 & 0.26 & 0.29 & 0.47 \\
\hline
\end{tabular}

Table 8 : Stagnant effective conductivity of the cylinders in $\mathrm{W} / \mathrm{m} / \mathrm{K}$

The full cylinder group is characterized by two morphological parameters: the length $\left(L_{c y l}\right)$ and the diameter $\left(D_{c y l}\right)$ of the cylinder. The full cylinders of the study have a similar equivalent particle diameter with a different ratio $L_{c y l} / D_{c y l}$. Despite this difference of external aspect, their values of $P e_{r}$ are similar. It confirms that the cylinders have similar abilities to distribute the heat in the medium under gas flow conditions. The porosity $(\varepsilon)$ of the packed bed of lengthened cylinders is higher than the porosity of the other ones (Table 2). The wall effect is more pronounced for the long cylinders and affects the stagnant thermal properties. For the higher bed density, the stagnant effective thermal conductivity is lower for equivalent particle size $\left(D_{P V}\right)$. The spheres $5.4 \mathrm{~mm}$, hollow cylinders $5 \times 5 \times 3$ and full cylinders $4 \times 8$ of $\beta \mathrm{SiC}$ have similar $k_{e f f, r a d, 0}^{g}$ which is much lower than the one of the full cylinders $5 \times 5 \times 3$.

Thus, in the aim of reducing radial gradient of temperature in a porous medium, the equilateral cylinders (ratio $L_{c y} / D_{c y l}=1$ ) are preferred. The full equilateral cylinders are recommended for the low flow rates and hollow equilateral cylinders for the high flow rates.

\subsection{The wall heat transfer coefficient}

The value of the Nusselt number at the wall $\left(N u_{\text {wall }}\right)$ is estimated with 2D-PH model and SM model. The comparison is done for all the particles of the Table 2. For $\operatorname{Re}<500$, the deviation between the models is below 5\%; however, for the higher Reynolds numbers, the $N u_{\text {wall }}(\mathrm{SM})$ overestimates the $N u_{\text {wall }}$ obtained with 2D-PH (i.e. around of $25 \%$ (maximum) of deviation for 
the highest Re). This result can be essentially explained by the difference between $T_{\text {wall }}$ estimated by the Eqs 9-11 and real $T_{\text {wall }}$.

In literature, it is generally observed that the heat transfer coefficient can be correlated with $R e$ number. Dixon (2012) suggests using Yagi and Kunii (1960) correlation (Eq.13). In this correlation the wall Nusselt number $\left(N u_{\text {wall }}\right)$ is a combination of wall Nusselt number without flow rate $\left(N u_{w a l l, 0}\right)$, the wall film Nusselt number $\left(N u_{w a l l}^{*}\right)$ and the fluid mechanical Nusselt number $\left(N u_{m}\right)$.

$N u_{\text {wall }}=N u_{\text {wall }, 0}+\frac{1}{\frac{1}{N u_{\text {wall }}^{*}}+\frac{1}{N u_{m}}}$

With $N u_{\text {wall }}^{*}=0.3 * \operatorname{Pr}^{1 / 3} \operatorname{Re}^{0.75}$

And $N u_{m}=0.054 \operatorname{Pr} R e$

In Figure 10, $N u_{\text {wall }}$ is estimated from the SM model.

$N u_{\text {wall,0 }}$ (estimated from the linear regression) and the calculated values (correlation) are compared in Table 9.

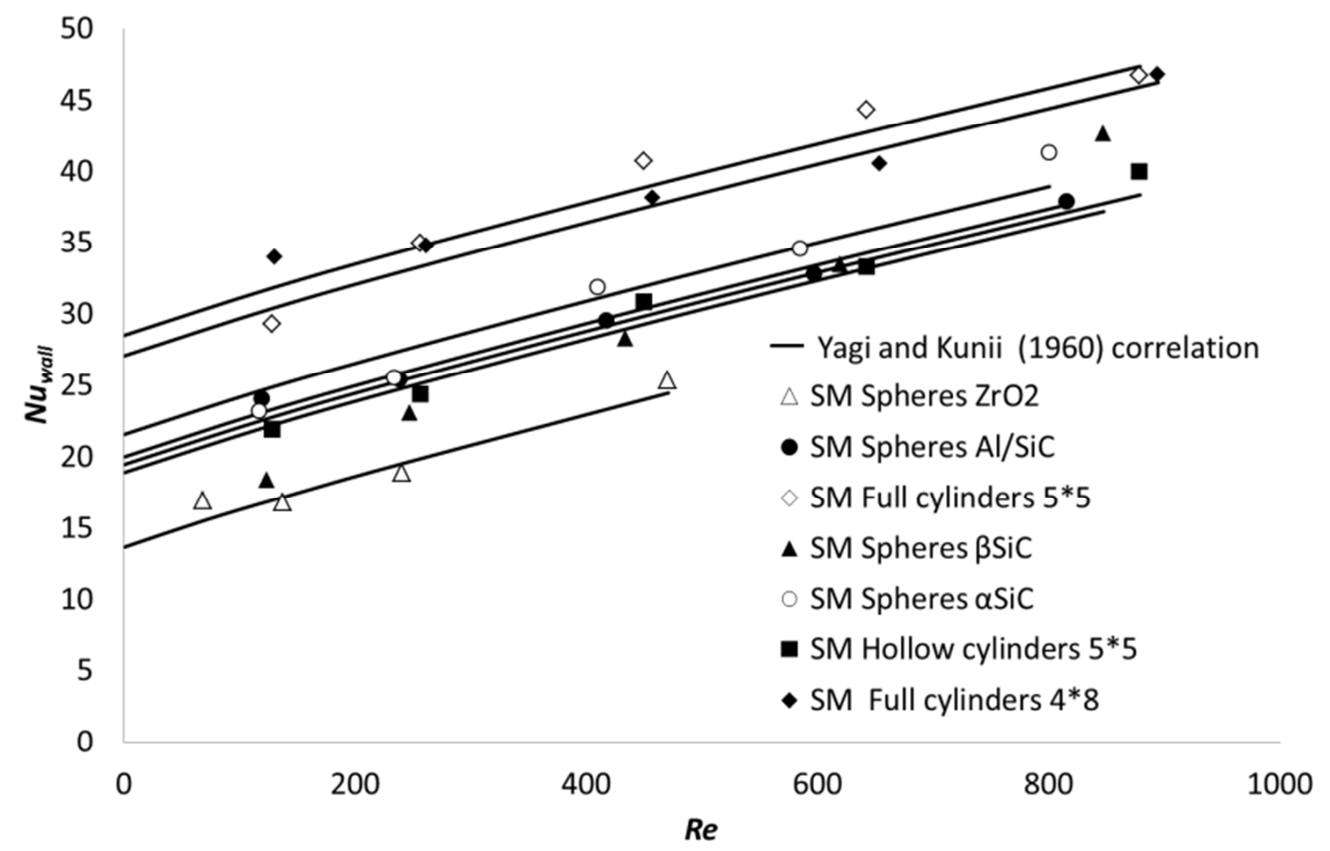

Figure 10 : Estimated $N u_{\text {wall }}$ vs the correlation (Yagi and Kunii, 1957)

According to Dixon (2012), Eq.13 represents very well the experimental data obtained in this work. It is important to note that this correlation can be used for the spheres, hollow and full cylinders. The main difference for the different supports is due to the $N u_{w a l l, 0}$ value. 
The spheres and hollow cylinders present similar values of $N u_{\text {wall,0 }}$ (Table 9) and the full cylinders the highest values of $N u_{\text {wall, } 0}$. The different values obtained are compared with the values of $N u_{w a l l, 0}$ calculated from Hennecke and Schlünder (1973) correlation.

\begin{tabular}{|c|c|c|}
\hline & Estimated $N u_{w a l l, 0}$ & Calculated $N u_{\text {wall,0 }}$ \\
\hline \multicolumn{3}{|l|}{ Spheres } \\
\hline$\alpha \mathrm{SiC}$ & 21.6 & 23.1 \\
\hline$\beta S i C$ & 18.9 & 18.7 \\
\hline Si/Al & 20.0 & 16.4 \\
\hline $\mathrm{ZrO}_{2}$ & 13.7 & 15.8 \\
\hline \multicolumn{3}{|l|}{ Cylinders } \\
\hline Full 4x8 & 27.1 & 27.1 \\
\hline Full 5x5 & 28.5 & 29.2 \\
\hline Hollow $5 \times 5 \times 3$ & 19.5 & 20.5 \\
\hline
\end{tabular}

Table 9 : Estimated and calculated $N u_{\text {wall }, 0}$ of spheres and cylinders

The estimated values are in the same order of magnitude than the calculated values. The maximal percentage of deviation is $22 \%$ for the particles of Si/Al. Full cylinders are the shape of particles with the most important heat transfer performances at the wall.

\subsection{Towards an optimal shape}

The shape of the particle affects the heat transfers (effective conductivity and coefficient at the wall) and the pressure drop. These three physical parameters can be optimized by an appropriate design of particle.

The external morphology has been studied by comparing the performances of spheres and full cylinders. Compared to the spheres, the full cylinders allow increasing heat transfers (effective conductivity and wall heat transfer) of the bed. However, the pressure drop is also increased. So, the cylindrical shape is the kind of particles which could be optimized. The ratio Lcyl/Dcyl and the presence of holes are the structural properties which can be optimized in order to improve the hydro-thermal performances of the packed bed.

The ratio $L c y l / D c y l$ does not seem to significantly affect the thermal transfer at the wall or the dynamic effective conductivity. However, it influences the static conductivity and the pressure drop. For iso-sizes particles (same $D_{P V}$ ), we observed that increasing Lcyl/Dcyl $(>1$ ) allows to reduce the pressure drop. It also decreases the static conductivity. For the high gas velocity, the main contribution for the effective conductivity is the dynamic part, and thus the static conductivity has a minor effect. However, the pressure drop of the bed is significantly decreased 
for the lengthened cylinders compared to the equilateral cylinders (around 20\%). Thus the ratio $L c y l / D c y l$ can be a key parameter for the optimization of the particle shape.

The inner holes affect the pressure drop in two different ways. On the one hand, the inner holes allow increasing de global porosity of the bed and consequently tend to decrease the pressure drop of the bed. On the other hand, the inner holes allow increasing the contact area solid/gas and thus tend to increase the pressure drop. So the size of the hole can have a negative and/or a positive effect on the pressure drop. Compared to the full cylinders the presence of the holes leads to decrease static conductivity but increase dynamic conductivity. In other words, the hollow particles are preferred for high gas flow rate and full particles for the low flow rate. The inner holes tend to decrease the heat transfer coefficient at the wall.

\section{Conclusions}

A new robust experimental set-up is presented. It allows to measure the pressure drop, axial and radial temperature profiles in packed bed without important disturb in the flow. The heat transfer coefficient (effective conductivity and convection at the wall) are estimated from the conventional 2D-PH model and analytical model. The estimations are similar and a good agreement with the main correlations of the literature is observed for the conventional particles. Different particle shapes and compositions were tested under similar air flow conditions. The main results are:

(i) the composition of the tested particles changes the stagnant effective conductivity, so high intrinsic conductivity materials are preferred for the low $\operatorname{Re}(<300)$

(ii) for the high Reynold, the dynamic contribution is more important, and only the shape of the particle is significant

(iii) at iso-pressure drop, the cylinders are generally preferred for the heat transfer intensification

(iv) the size of the cylinder (i.e. $L c y l / D c y l$ ) and the diameter of the inner holes are morphological parameters which can be optimized in order to improve the thermal performance and the pressure drop of the catalytic packed bed.

Finally, the present work introduces a robust experimental setup and a simple procedure in order to estimate the key parameters (for the design of reactors). This method could be used to characterize (in chemical engineering point of view) the original catalytic supports (e.g. foams, incurved cylinders) and/or mixing of different supports and will be subject of the future works.

Appendix I: Axial and radial positions of the thermocouples

Names $\quad \mathbf{r}\left(\mathbf{1 0}^{-3} \mathrm{~m}\right) \quad \mathbf{z}\left(\mathbf{1 0}^{-3} \mathrm{~m}\right)$




\begin{tabular}{ccc}
\hline Th0-1 & 1,5 & 0 \\
Th0-2 & 4,5 & 0 \\
Th0-3 & 7,5 & 0 \\
Th1-1 & 7,1 & 50 \\
Th1-2 & 10,2 & 50 \\
Th1-3 & 13 & 50 \\
Th2-2 & 5,4 & 100 \\
Th2-3 & 8,9 & 100 \\
Th3-2 & 4,7 & 150 \\
Th3-3 & 7,5 & 150 \\
Th4-2 & 4,5 & 150 \\
Th4-3 & 7,4 & 150 \\
Th5-1 & 6,6 & 200 \\
Th5-2 & 9,7 & 200 \\
Th5-3 & 13 & 200 \\
Th6-2 & 4,6 & 250 \\
Th6-3 & 7,3 & 250 \\
Th7-1 & 7,1 & 300 \\
Th7-2 & 9,4 & 300 \\
Th7-3 & 13 & 300 \\
Th8-2 & 4,7 & 350 \\
Th8-3 & 7,5 & 350 \\
Th9-1 & 6,8 & 400 \\
Th9-2 & 10,2 & 400 \\
Th9-3 & 13 & 400 \\
Th10-2 & 4,5 & 450 \\
Th10-3 & 7,7 & 450 \\
\hline
\end{tabular}

Table 10: Axial and radial positions of the tri-thermocouples from the center of the tube (Th- 1 the longest and Th- 3 the smallest)

Appendix II: Uncertainty on the effective radial thermal conductivity

$k_{\text {eff,rad }}^{g}=\frac{\varphi_{h}}{2 * \pi * \mathrm{~L}_{\text {wire }}} * \frac{\ln \left(\frac{R}{r}\right)}{\left(T-T_{r=R}\right)}$

From the analytical solution of the Fourier's equation, the sensitivity of $k_{\text {eff,rad }}^{g}$ to the variables is calculated and the absolute uncertainty is defined by Stasiek et al. (1996) : 
$\delta k_{\text {eff }, \mathrm{rad}}^{g}=\left[\sum_{i=1}^{N}\left(\frac{\partial k_{e f f, r a d}^{g}}{\partial x_{i}} * \delta x_{i}\right)^{2}\right]^{0.5}$

$\delta:$ Absolute uncertainty

$x_{i}:$ Variables

$$
\begin{aligned}
& \frac{\partial k_{e f f, r a d}^{g}}{\partial \Delta T} \delta \Delta T=-\frac{\varphi_{h}}{2 * \pi * \mathrm{~L}_{\text {wire }}} * \frac{\ln \left(\frac{R}{r}\right)}{\Delta T^{2}} * \delta \Delta T \\
& \frac{\partial k_{e f f, r a d}^{g}}{\partial R} \delta R=\frac{\varphi_{h}}{2 * \pi * \mathrm{~L}_{\text {wire }}} * \frac{1}{\Delta T * R} * \delta R \\
& \frac{\partial k_{e f f, r a d}^{g}}{\partial r} \delta r=-\frac{\varphi_{h}}{2 * \pi * \mathrm{~L}_{\text {wire }}} * \frac{1}{\Delta T * r} * \delta r \\
& \frac{\partial k_{e f f, r a d}^{g}}{\partial \varphi_{h}} \delta \varphi_{h}=\frac{\ln \left(\frac{R}{r}\right)}{2 * \pi * \mathrm{~L}_{\text {wire }} * \Delta T} * \delta \varphi_{h}
\end{aligned}
$$

For instance: $\mathrm{Al} / \mathrm{Si}$ spheres and $u_{f}=1,8 \mathrm{~m} / \mathrm{s}$ :

$$
\begin{aligned}
& r=7.5 \mp 0.5 \mathrm{~mm} \\
& R=13 \mp 0.1 \mathrm{~mm} \\
& \Delta T=4 \mp 0.2^{\circ} \mathrm{C} \\
& \varnothing=38.1 \mp 3.1 \mathrm{~W} \\
& \frac{\partial k_{e f f, r a d}^{g}}{\partial \Delta T} \delta \Delta T=0.0712 \\
& \frac{\partial k_{e f f, r a d}^{g}}{\partial R} \delta R=0.0199 \\
& \frac{\partial k_{e f f, r a d}^{g}}{\partial r} \delta r=0.1726 \\
& \frac{\partial k_{e f f, r a d}^{g}}{\partial \varphi_{h}} \delta \varphi_{h}=0.1160 \\
& \delta k_{e f f, r a d}^{g}=\sqrt{0.0712^{2}+0.0199^{2}+0.1726^{2}+0.1160^{2}}=0.22 \frac{W}{m * K}
\end{aligned}
$$

The uncertainty is calculated for different particles and gas flow rates; the uncertainty is included between $14.5 \%$ and $15.5 \%$ so we consider an uncertainty of $15 \%$ on the estimation of $k_{e f f, r a d}^{g}$. Appendix III: Radial temperature profile (experimental and Fourier's equation) of two different particle shapes in the same experimental conditions $\left(\mathrm{u}_{f}=1,8 \mathrm{~m} / \mathrm{s}\right)$ 


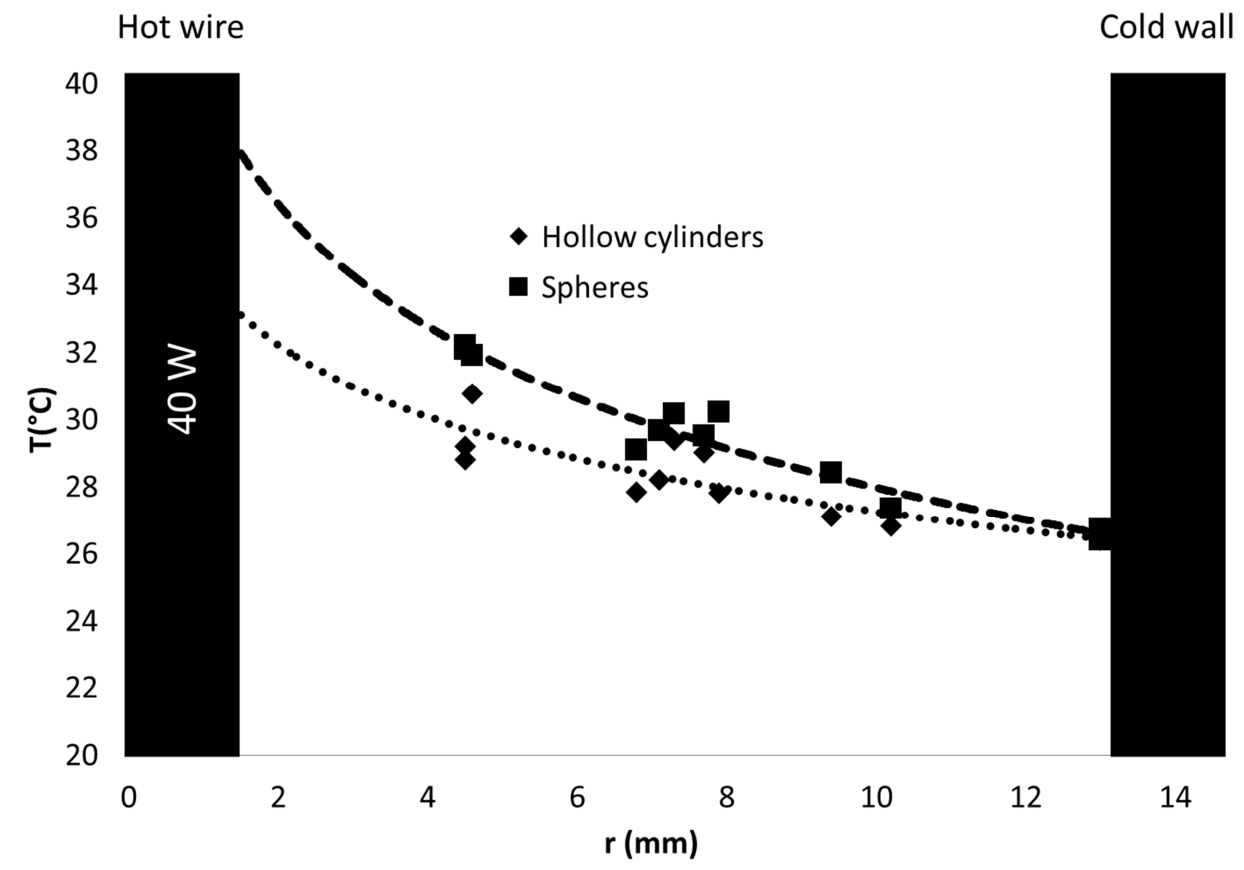

\section{Acknowledgments}

The authors gratefully acknowledge J.P. Valour (LAGEP), S. Urbaniak (LAGEP) and F. Bornette (LGPC) who helped for the building and the understanding of the pilot. The authors would like to thanks Sicat and NorPro for providing samples.

\section{References}

Bartholomew, C.H., 2001. Mechanisms of catalyst deactivation. Appl. Catal. Gen. 212, 17-60.

Bauer, R., Schlünder, E.U., 1978. Effective Radial Thermal Conductivity of Packings in Gas Flow. Part I Convective Transport Coefficient. Int. Chem. Eng. 18, 181-188.

Bey, O., Eigenberger, G., 2001. Gas flow and heat transfer through catalyst filled tubes. Int. J. Therm. Sci. 40, 152-164.

Bhattacharyya, D., Pei, D.C.T., 1975. Heat transfer in fixed bed gas—solid systems. Chem. Eng. Sci. 30, 293-300.

Bianchi, E., Heidig, T., Visconti, C.G., Groppi, G., Freund, H., Tronconi, E., 2012. An appraisal of the heat transfer properties of metallic open-cell foams for strongly exo-/endo-thermic catalytic processes in tubular reactors. Chem. Eng. J. 198-199, 512-528. https://doi.org/10.1016/j.cej.2012.05.045

D. G. Bunnell, H. B. Irvin, R. W. Olson, and J. M. Smith, "Effective thermal conductivities in gas-solid systems,” Ind. Eng. Chem., vol. 41, no. 9, pp. 1977-1981, 1949.

Calverley, E.M., Witt, P.M., Sweeney, J.D., 2013. Reactor runaway due to statistically driven axial activity variations in graded catalyst beds: Loading from pre-measured single tube aliquots. Chem. Eng. Sci. 90, 170-178. https://doi.org/10.1016/j.ces.2012.12.017 
Chueh, C.C., Bertei, A., Pharoah, J.G., Nicolella, C., 2014. Effective conductivity in random porous media with convex and non-convex porosity. Int. J. Heat Mass Transf. 71, 183188. https://doi.org/10.1016/j.ijheatmasstransfer.2013.12.041

De Wasch, A.P., Froment, G.F., 1971. A two dimensional heterogeneous model for fiexd bed catalytic reactors.pdf. Chem. Eng. Sci. 26, 629-634.

Dixon, A.G., 2012. Fixed bed catalytic reactor modelling-the radial heat transfer problem. Can. J. Chem. Eng. 90, 507-527. https://doi.org/10.1002/cjce.21630

Dixon, A.G., 1988. Correlations for wall and particle shape effects on fixed bed bulk voidage. Can. J. Chem. Eng. 66, 705-708.

Dixon, A.G., Ertan Taskin, M., Nijemeisland, M., Stitt, E.H., 2008. Wall-to-particle heat transfer in steam reformer tubes: CFD comparison of catalyst particles. Chem. Eng. Sci. 63, 22192224. https://doi.org/10.1016/j.ces.2008.01.017

Dixon, A.G., Walls, G., Stanness, H., Nijemeisland, M., Stitt, E.H., 2012. Experimental validation of high Reynolds number CFD simulations of heat transfer in a pilot-scale fixed bed tube. Chem. Eng. J. 200-202, 344-356. https://doi.org/10.1016/j.cej.2012.06.065

Edouard, D., Truong Huu, T., Pham Huu, C., Luck, F., Schweich, D., 2010. The effective thermal properties of solid foam beds: Experimental and estimated temperature profiles. Int. J. Heat Mass Transf. 53, 3807-3816. https://doi.org/10.1016/j.ijheatmasstransfer.2010.04.033

Eisfeld, B., Schnitzlein, K., 2001. The influence of confining walls on the pressure drop in packed beds.pdf. Chem. Eng. Sci. 42, 2163-2171.

Ergun, S., 1952. Fluid flow through packed columns. Chem. Eng. Prog. 48, 89-94.

Forzatti, P., Lietti, L., 1999. Catalyst deactivation. Catal. Today 52, 165-181.

Glaser, M.B., Thodos, G., 1958. Heat and momentum transfer in the flow of gases through packed beds. AIChE J. 4, 63-68.

Gunn, D.J., Ahmad, M.M., Sabri, M.N., 1987. Radial heat transfer to fixed beds of particles.

Guo, X., Sun, Y., Li, R., Yang, F., 2014. Experimental investigations on temperature variation and inhomogeneity in a packed bed CLC reactor of large particles and low aspect ratio. Chem. Eng. Sci. 107, 266-276. https://doi.org/10.1016/j.ces.2013.12.032

Hennecke, F.-W., Schlünder, E.U., 1973. Wärmeübergang in beheizten oder gekühlten Rohren mit Schüttungen aus Kugeln, Zylindern und Raschig-Ringen. Chem. Ing. Tech. 45, $277-$ 284.

Macdonald, I.F., El-Sayed, M.S., Mow, K., Dullien, F.A.L., 1979. Flow through porous mediathe Ergun equation revisited. Ind. Eng. Chem. Fundam. 18, 199-208.

Nemec, D., Levec, J., 2005. Flow through packed bed reactors: 1. Single-phase flow. Chem. Eng. Sci. 60, 6947-6957. https://doi.org/10.1016/j.ces.2005.05.068

Pangarkar, K., Schildhauer, T.J., van Ommen, J.R., Nijenhuis, J., Moulijn, J.A., Kapteijn, F., 2009. Experimental and numerical comparison of structured packings with a randomly packed bed reactor for Fischer-Tropsch synthesis. Catal. Today 147, S2-S9. https://doi.org/10.1016/j.cattod.2009.07.035

Romkes, S.J, F.M Dautzenberg, van den Bleek, C, Calis, H.P, 2003. CFD modelling and experimental validation of particle-to-fluid mass and heat transfer in a packed bed at very low channel to particle diameter ratio. Chem. Eng. J. 96, 3-13. https://doi.org/10.1016/j.cej.2003.08.026

Saber, M., Pham-Huu, C., Edouard, D., 2012. Axial Dispersion Based on the Residence Time Distribution Curves in a Millireactor Filled with $\beta$-SiC Foam Catalyst 15011-15017. 
Sadeghi, E., Hsieh, S., Bahrami, M., 2011. Thermal conductivity and contact resistance of metal foams. J. Phys. Appl. Phys. 44, 125406. https://doi.org/10.1088/0022-3727/44/12/125406

Smirnov, E.I., Kuzmin, V.A., Zolotarskii, I.A., 2004. Radial thermal conductivity in cylindrical beds packed by shaped particles. Chem. Eng. Res. Des. 82, 293-296.

Stasiek, J., Collins, M.W., Ciofalo, M., Chew, P.E., 1996. Investigation of flow and heat transfer in corrugated passages-I. Experimental results. Int. J. Heat Mass Transf. 39, 149-164.

van Antwerpen, W., du Toit, C.G., Rousseau, P.G., 2010. A review of correlations to model the packing structure and effective thermal conductivity in packed beds of mono-sized spherical particles. Nucl. Eng. Des. 240, 1803-1818. https://doi.org/10.1016/j.nucengdes.2010.03.009

Vatcha, S.R., 1998. Techniques for creating catalysts with superior thermal properties. Colloids Surf. Physicochem. Eng. Asp. 133, 99-105.

Wen, D., Ding, Y., 2006. Heat transfer of gas flow through a packed bed. Chem. Eng. Sci. 61, 3532-3542. https://doi.org/10.1016/j.ces.2005.12.027

Xu, Y., Zangvil, A., Landon, M., Thevenot, F., 1992. Microstructure and Mechanical Properties of Hot-Pressed Silicon Carbide-Aluminum Nitride Compositions. J. Am. Ceram. Soc. 75, 325-333.

Yagi, S., Kunii, D., 1960. Studies on heat transfer near wall surface in packed beds. AIChE J. 6, 97-104.

Yagi, S., Kunii, D., 1957. Studies on effective thermal conductivities in packed beds. AIChE J. 3, 373-381.

Zehner, P., Schlünder, E.U., 1970. Wärmeleitfähigkeit von Schüttungen bei mäls sigen Temperaturen. Chem. Ing. Tech. 42, 933-941.

Zhu, X., Lu, X., Hildebrandt, D., Glasser, D., 2010. Study of radial heat transfer in a tubular Fischer- Tropsch synthesis reactor.pdf. Ind. Eng. Chem. Res. 49, 10682-10688.

Zhu, X., Lu, X., Liu, X., Hildebrandt, D., Glasser, D., 2014. Heat transfer study with and without Fischer-Tropsch reaction in a fixed bed reactor with $\mathrm{TiO} 2, \mathrm{SiO} 2$, and $\mathrm{SiC}$ supported cobalt catalysts. Chem. Eng. J. 247, 75-84. https://doi.org/10.1016/j.cej.2014.02.089 